\title{
EL DISCURSO PARÓDICO AFRO-OCCIDENTAL DE LOS ESCRITORES GUINEANOS CONTEMPORÁNEOS
}

\author{
POR \\ CRISTIÁn H. RicCI \\ Universidad de California, Merced
}

Este estudio se enfocará en la literatura guineana del siglo xxI, la que comprende el "Nuevo costumbrismo nacional" o "Nueva narrativa nacional". Dentro de este grupo, resaltaré los trabajos de José Fernando Siale Djangany (Cenizas de Kalabó y Termes 2000 y Autorretrato con un infiel 2007), de Maximiliano Nkogo Esono (Nambula 2000) y de Juan Tomás Ávila Laurel (Avión de ricos, ladrón de cerdos 2008). El artículo cerrará con el novísimo escritor César Mba (El porteador de Marlow. Canción negra sin color 2007). Analizaré cómo estos textos y autores cuestionan tanto la autenticidad del proceso de transición africana de cara a un moderno estado-nación, "ajustándose" a los modelos "democráticos-civilizados" de Occidente. Las tres nociones clave sobre las que se apoya mi análisis girarán en torno a la desjerarquización y rejerquización de la cultura europea y occidental, la relación entre la parodia, la transgresión y el lenguaje como fenómeno social.

El lenguaje paródico en los textos de los autores guineoecuatorianos a analizar en este artículo se exhiben, si bien con ciertos matices, como lenguaje "no inocente" (Glissant 39), que actúa, por una parte, como lente transparente a través del cual los personajes ven y evalúan su mundo; mientras que, por otro lado, dicho lenguaje se señala a sí mismo ("desviándol[o] y derribándol[o] no mediante síntesis, sino mediante aperturas lingüísticas", Glissant 42), revelando la verdadera naturaleza cultural de los mitos y valores que constituyen los sistemas ideológicos de la comunidad autóctona guineana desde la época colonial, pasando por el reordenamiento clasista durante la dictadura de Francisco Macías Nguema, hasta arribar a la conformación de una burguesía nacional. De esta manera, como lectores, pasamos a observar cómo es narrada la experiencia unívoca y necesaria de acontecimientos en los textos que describen los sucesos de la colonia a una multiplicidad de situaciones capaz de estimular actitudes de acción o interpretación siempre distintas, subvirtiendo, de alguna u otra manera, categorías y géneros y, al mismo tiempo, brindando posibilidades hermenéuticas tendientes a la utilización transgresora de los cánones que conforman las "grandes narrativas" occidentales. De allí que el 
dialogismo y la intertextualidad de la literatura de Guinea Ecuatorial contemporánea se debe no sólo a su carácter "marginal" respecto a la cultura/literatura "occidental", sino también a la representación del brutal proceso de asimilación por parte de los guineanos de culturas ajenas, incluido el choque violento de un punto de vista cristiano, la continuación de las desigualdades de género, la explotación de la clase obrera y/o la campesina (que se sigue dando incluso luego de conseguida la independencia), y de otros y muy diversos tipos de colonialismos (o neocolonialismos) que ponen en jaque la aplicación de teorías poscolonialistas de manera indiscriminada. Ergo, en este estudio no siempre poscolonialismo será sinónimo de descolonización. Ya en el ámbito de las élites guineanas educadas y "viajadas" como contraparte de las "élites descerebradas y subordinadas", que refiere Aimé Césaire (21), se resalta el hecho de la afluencia de un grupo de profesionales e intelectuales (incluida la mayoría de los autores analizados en este artículo y/o la ligada, de alguna u otra forma, al gobierno de turno), que luego de realizar sus estudios en Europa y de haberse impregnado de cultura occidental, vuelven a Guinea; y, por último, el avance gradual de un capitalismo moderado (formador de una pequeña burguesía) hasta alcanzar el paroxismo del capitalismo salvaje a partir, entre otras cosas, del descubrimiento de petróleo que ha llevado a aumentar el PIB per capita hasta US\$50.000 en el último trienio (Nistal Rosique 102-03, Lewis 11).

José Fernando Siale Djangany, por repetir lo que se dice en la semblanza que acompaña a Autorretrato con un infiel, intenta superar complejos del tiempo de la colonización y de la posterior descolonización. ${ }^{1}$ (TRASICION) El Nobel de literatura Derek Walcott utiliza los conceptos de mimetismo y pantomima para referirse a la proyección especular del subalterno (aunque no utiliza esta palabra y se refiere más bien al ámbito antillano/americano, no al africano) basado en referencias y simulaciones, si bien distorsionadas/parodiadas, del orden socio-moral y de la jerarquización lineal de la metrópolis (259). Allí reposaría el universo mítico entretejido de Autorretrato con un infiel con una normalidad inmune a los absurdos y esoterismos que van apareciendo, todo ello combinado con pedazos de historia local disfrazada donde se da cuenta de las relaciones entre la colonia guineana y las antiguas metrópolis portuguesa y española (Puerto Galo y Cabo Norte, respectivamente). Por ende, no es arbitrario que la novela abra con la mención del "antiguo copista, hoy escritor riguroso conocido como Juvenal de Golas" (19), documentando, sin que él lo sepa, una "liturgia maronita entreverada de sincretismo ortodoxo occidental" (19). El singular cronista no hace más que recordar los estudios y artículos que aparecían en La Guinea Española por los misionarios claretianos

\footnotetext{
1 A propósito del título, en la presentación del libro en el Centro Cultural Español de Malabo, el autor explicó la razón del título del libro: "Estando en casa de unos amigos vi el cuadro de Frida Kahlo Autorretrato con mono y pensé que era tan fea que no se sabía quién era el mono". En el caso de su título, pretende hacernos reflexionar sobre quién es el infiel, el colonizador o el colonizado (Nistal Rosique $125)$.
}

Revista Iberoamericana, Vol. LXXX, Núms. 248-249, Julio-Diciembre 2014, 967-985 
de Bioko y que apuntaban a representar "el pensamiento de los nativos [...] fábulas, proverbios y canciones" con la intención de "promocionarlos e inmortalizarlos" ( $L a$ Guinea Española). Sin embargo, -continúo con la analogía de Walcott sobre "mimic men" y "simulations of self-discovery" (257-264) - llegará una instancia en la novela en la que no sólo el cronista pasa a un segundo plano y deja de efectuar su labor de traductor/"traidor" de las historias locales, sino que también el sujeto subalterno dejará de mirarse en el espejo del opresor en el afán de mantener un balance con la moralidad impuesta por la religión católica, para manifestar sentimientos de justicia social, dignidad, memoria racial y tradición, cortar el cordón umbilical y promover un retorno -aunque utópico y plagado de obstáculos impuestos en combinación tanto por el colonizador como por los sujetos (neo)coloniales ${ }^{2}-$ a las relaciones sociales solidarias de sus antepasados, a su naturaleza guerrera y a los ritos religiosos ancestrales.

Las mencionadas tradiciones orales y ritos habían sido revisitadas y desarrolladas por los primeros autores guineanos (Daniel Jones Mahatma y Leoncio Evita) en una mezcla que M'bare N'gom (siguiendo quizá a Ngũgĩ wa Thiong'o en Detained: $A$ Writer's Prison Diary) ha denominado agentes intermediarios que sintetizaban la figura tradicional del griot o djéli y las formas de escritura canónica occidental (412). En esta vena, y extendiendo el rol intermediario que N'gom acredita sólo a los pioneros de la literatura guineana hasta los autores contemporáneos, observo que José Siale desarrolla en Autorretrato con un infiel una representación polifónica de la transición de la época colonial a la poscolonial que actúa como una suerte de mecanismo escriturario para evitar la pérdida de la historia. En este sentido, las figuras literarias de historiadores, antropólogos, sociólogos y misionarios europeos actúan de tal forma que adulteran y conspiran con el fin de destruir los archivos materiales de la historia africana. El lienzo del Padre Delatorre, "Autorretrato con un infiel", del cual es tomado el título de la novela, es una declaración irónica que intenta aseverar que el subalterno no puede todavía retratarse a sí mismo. En otras palabras, el personaje africano todavía “debe ser" dibujado/ tutelado por los poderes dominantes (aunque paradójicamente ignorantes) y siguiendo sus propios criterios estéticos y morales, de allí que pinta un segundo retrato: "Soy negro, pero hermoso hijo de Dios" (26). Esta representación del Otro como "humano, pero no tan humano" (Lord Rosebery citado en Bhabha, "Of Mimicry" 265), aunque irrisoria y ambivalente, como bien lo explicita Said en Orientalismo (240), se convierte muchas veces en estrategias elusivas y efectivas del poder y "conocimiento" del colonizador, con todo lo negativo que ello conlleva. El otro elemento revelador de la novela de José

2 Al fin y al cabo, como observan Césaire y Glissant, no es un grave problema el "intento utópico y estéril de la vuelta al pasado", sino más bien un esfuerzo para "ir más lejos", "crear una nueva sociedad con todo el poder productivo de los tiempos modernos en conjunto con la fraternidad distintiva de los viejos tiempos" (Césaire 31, Glissant 33, 96, 101).

Revista Iberoamericana, Vol. LXXX, Núms. 248-249, Julio-Diciembre 2014, 967-985 
Siale se sitúa en la figura del tradicional cuentacuentos al que se le pregunta cuál es el significado subliminal de sus narraciones y es incapaz de responder: "No lo sé [...]. Yo sólo cuento historias, no entiendo mucho de aclaraciones"(78). Mientras que en la novela la lectura también es censurada, los personajes autóctonos se encuentran atrapados en un espacio en el que son incapaces de hablar de su propia cultura y/o de tener acceso a la cultura caligráfica. De allí que las ceremonias tradicionales y las costumbres han perdido sus significados originales y actúan como simples "representaciones" vacías de contenido, en sus formas puras. Ahora bien, si en la novela existe un intento de nulidad del sujeto poscolonial desposeído tanto de la oralidad como de la escritura, también es digno destacar que entre los procesos escriturarios de imitación y burla, la mission civilisatrice es desestabilizada a través de procedimiento similar al que Homi Bhabha le atribuye a la adulteración (rayana al esperpento, podríamos añadir) promulgada por la "ambivalence of mimicry" ("Of Mimicry" 266, bastardillas en el original). ${ }^{3}$ Lo que emerge, en cambio, es una escritura, un modo de representación, que margina la monumentalidad de la Historia (contada por el europeo) y se mofa del poder español/ católico como modelo.

En Autorretrato con un infiel, los topónimos escogidos y los nombres propios apenas ocultan realidades geográficas e históricas ineludibles: Póor Donanfer, la isla, tapuja claramente a Fernando Poo; Isco de Corr es la isla de Corisco, Carlos San Basilio por Bahía de San Carlos, Kauré por Ureka, Papa-cup por Kupapa. Franck Nkóh, el dictador instalado en la metrópoli, empeñado en manipular el país una vez concedida una "tutelada" independencia, es Francisco Franco, el marqués de Alejo de Argel por el Duque de Arjelejo y el "Tratado del Oso Pardo" por el "Tratado del Pardo". Junto a todos estos elementos, está la presencia de tradiciones mágicas y atavismos que se nos van desvelando por medio del vocabulario en lenguas autóctonas y que conviven sin aparente contradicción con la impávida cotidianeidad de los personajes. ${ }^{4}$ Se observa entonces en la novela de José Siale la introducción de elementos extraordinarios que recuerdan al realismo mágico de los García Márquez, Isabel Allende o Vargas Llosa:

No era como los demás jóvenes [...] [D]escubrió que Hermenegildo tenía cuatro ojos, dos de ellos inmateriales con los que le era posible distinguir aspectos del mundo

\footnotetext{
"What they all share [la imitación y la burla] is a discursive process by which the excess or slippage produced by the ambivalence of mimicry (almost the same, but not quite) does not merely 'rupture' the discourse, but becomes transformed into an uncertainty which fixes the colonial subject as a "partial" presence. By 'partial' I mean both 'incomplete' and 'virtual.' It is as if the very emergence of the 'colonial' is dependent for its representation upon some strategic limitation or prohibition within the authoritative discourse itself. The success of colonial appropriation depends on a proliferation of inappropriate objects that ensure its strategic failure, so that mimicry is at once resemblance and menace" (bastardillas en el original, 266).

4 La introducción de la trama con saga familiar también se encuentra en Cenizas de Kalabó y Termes.
}

Revista Iberoamericana, Vol. LXXX, Núms. 248-249, Julio-Diciembre 2014, 967-985 
inmaterial, del mundo de lo oculto y también percibir a aquellos que ya no estaban entre los vivos. (37)

Sin embargo, este aparente "realismo mágico africano" (que en otro sitio denominé, siguiendo a Senghor, "realismo mítico"5) puede tener unas relaciones más complejas que la de su análogo latinoamericano. En este sentido, es preciso tomar suficiente distancia y evitar contemplar la obra con la autocomplacencia de cierto multiculturalismo eurocentrista que busca en lo exótico, mágico y sensual (Glissant 114, Said 10) las claves para una lectura romántica de una "Africa-centred consciousness" (Gordimer 5), aunque “dull, drab, flippant” (Ngara 5), incapaz de pensamiento crítico original; o que se regocija por el hecho de encontrar fenómenos de persistencia de la lengua del opresor, incluso después de un intento de descolonización/liberación basado, si bien en parte, en la imposición de la llamada négritude, "the sum of the cultural values of the Black World" (Senghor 184, bastardillas en el original). "Négritude tardía", podríamos designarle, cuyo equivalente se encontraría en el término "comprador bourgeoisie", acuñado por Ngũgĩ wa Thiong'o (157), que en el caso de José Siale -como en el de la mayoría de los autores de su generación que utilizan el castellano como lengua literaria- evidencia la naturaleza de una literatura pequeñoburguesa que intenta, por un lado, confrontar, en forma de "diálogo y reciprocidad" (Senghor 186), el racismo y fanatismo religioso europeo $\mathrm{y}$, a la vez, refleja la ascensión a puestos de poder de la sección patriótico-nacionalista de la misma pequeña burguesía antes y después de la independencia. ${ }^{6}$ Más allá de la posible lectura neocolonialista, y teniendo en cuenta las particularidades trágicas de Guinea Ecuatorial, tal vez haya que ver en la novela de José Siale un proceso de maduración capaz de asumir el hecho de que la historia y la memoria no tienen marcha atrás, y de que es lícito sacar provecho de todo lo que llega a las manos del autor por educación o por cultura, pero de ninguna manera renunciar a describir cómo cada grupo o personaje reflejado en el texto se apropia de y reinterpreta los productos simbólicos ajenos, condiciones esenciales para que la interpretación y rejerarquización tanto de las historias de explotación y sometimiento como de la evolución de estrategias de resistencia "no se atavíen en la mera utilización de recursos mágico realistas de comprensión universal" (García Canclini 31).

La virtud de la historia de generar consecuencias de todo tipo sobre el ser humano y sus sociedades se ejemplifica bien en la compleja novela del autor de Bioko. Autorretrato

5 Ricci, Cristián H. "African voices in Conteporary Spain".

6 Pequeña burguesía que Ngũgĩ wa Thiong’o describe como psicológicamente oscilante: "It can be swept to activity by the masses at a time of revolutionary tide; or to be driven to silence, fear, cynicism, withdrawal into self-contemplation, existential anguish, or collaboration with the powers-to-be at times of reactionary times. In Africa this class has always oscillated between the imperialistic bourgeoisie and its comprador neo-colonial ruling elements on the one hand, and the peasantry and the working classes (the masses) on the other" (158).

Revista Iberoamericana, Vol. LXXX, Núms. 248-249, Julio-Diciembre 2014, 967-985 ISSN 0034-9631 (Impreso) 
con un infiel tiene mucho de denuncia de la tiranía y de la represión, vengan de donde vengan, y puede considerarse en más de un aspecto un manifiesto vivo del punto en el que se encuentra Guinea Ecuatorial tras las tribulaciones de estos dos últimos siglos. Algunos nombres hablan por sí solos: la depravada capital, Civilianjaïl (en clara, aunque anacrónica, referencia al Decreto 115 de 1971 promulgado por Macías en el que se suspendían las garantías constitucionales, se encarcelaba y asesinaba a las voces de ciudadanos disidentes), el sanguinario agente del orden Hadèsfaya Orugo Matàs, el procurador Wengo, posible trasunto del último gobernador español, Francisco Núñez Rodríguez, y el déspota Nicomedes Espíritu Sesinado, alter ego del dictador Macías, entre otros. Baltasar Bulëtyé, educado en la misión, violará un día los cerrojos y la cerradura del cofre donde se encuentra el amuleto de sus antepasados. Desde ese momento iniciará su retirada en el "denso bosque" para conservar el objeto ancestral: el brazalete eppá de tyíbbö. La errancia es la que induce a Baltasar a dejar los pensamientos de sistema por los pensamientos de indagación de lo real, los pensamientos de traslación, que son también, según Glissant, pensamientos de ambigüedad y de incertidumbre, escudo contra la intolerancia y el sectarismo (130). Su primo Hermenegildo Reho Bulëtyé le avisará del mal estado de salud de Bosquejo Delatorre, hermano de la misión al que aprecia como pupilo. De nuevo en la misión, Bosquejo le pedirá a Baltasar que busque el libro de cuero rústico denominado Kaurhemongo. Cansado de los años de protección del talismán o intuyendo su posible muerte, Baltasar dejará el libro en manos de Hermenegildo. Nicomedes Espíritu Sesinando pactará con Franck Nkóh la autonomía y posterior independencia del país, dando a entender que el "circuito de servicios mutuos y complicidad entre nuevos y autóctonos tiranos con los viejos" no se desvirtúa, sino que se fortalece, haciéndose las modernas dictaduras "más efectivas y eficientes" (Césaire 22, 24).

En consecuencia, José Siale consigue armonizar e incorporar en su literatura las dos culturas de las que ha bebido, siempre consciente de evitar la "romantización" de las costumbres pre-coloniales, como, durante el periodo colonial, de narrar las culturas autóctonas de manera distante, explotadas pero con una rica e intacta herencia cultural a la espera de ser redescubierta y reivindicada de manera benévola y bienhechora. Creo que el siguiente pasaje en el que un grupo de nativos ("gracórcitos") asalta y destruye un pueblo habitado por otra tribu de nativos ("Jubilea") ilustra de manera cabal la idea del bon savage que algunos intelectuales afiliados a corrientes poscoloniales (particularmente del "primer mundo") pretenden elevar a categorías glorificantes: "Ostentaremos ilusoriamente la bandera blanca para inducirles a bajar la guardia. Y al final del combate

Posición paralela a los investigadores de los años cincuenta que Césaire llamaba "académicos gotosos", psicólogos, sociólogos, et al., ensimismados en autocomplacientes generalizaciones sobre los "primitivos" $(33,35)$.

Revista Iberoamericana, Vol. LXXX, Núms. 248-249, Julio-Diciembre 2014, 967-985 
haremos uso de métodos de destrucción enérgicos e infligiremos sufrimiento, saqueo, pillaje, venganza [...] dispuestos a matar a niños y ancianos" (183). Lo importante, en definitiva, es que la narración finaliza paradójicamente con la misma hipocresía y genocidio que propició la mayoría de las empresas coloniales, esta vez hecha por parte de una de las comunidades autóctonas, articulando las distorsiones raciales, culturales, y la diferencia histórica que rechaza el deseo narcisista de autoridad colonial (Walcott 264, Bhabha, "Of Mimicry" 268).

Cenizas de Kalabó y Termes, primera novela del autor de Bioko, como dice Marvin Lewis: "represents a somewhat different approach to Equatorial Guinean narrative art" (12). Desobedeciendo los consejos de un amigo que le decía que no se debía ni se podía escribir hasta dentro de cien años, José Siale afirma que "censura rima con literatura y con lectura" (14) y escribe esta novela con la que, según sus propias palabras en el prólogo, "alberg[a] la esperanza de despertar entusiasmo, ambición intelectual y literaria en otros ecuatoguineanos" (15). Con un estilo refinadamente irónico, la novela narra en estilo autobiográfico la vida de Ildefonso Wilson Peleté, desde su nacimiento e infancia en una zona pobre y sucia de Santa Isabel (actual Malabo), su adolescencia y juventud, pasando por su huida y exilio en Libreville. De allí partirá a París para luego regresar a su patria. A pesar de sus buenas intenciones, Wilson Peleté no prosperará en su intento de mejorar el país: la realidad de la pobreza, epidemias, degradación y corrupción sesgarán su esfuerzo; haciendo válida, de esta forma, la aserción de Frantz Fanon: "The native intellectual who comes back to his people by way of culture achievements behaves like a foreigner [...]. [T] he ideas he expresses and the preoccupations he is taken up with have no common yardstick to measure the real situation the men of his country know" (208). Situada en la transición del colonialismo a la construcción de un estado africano independiente, Cenizas de Kalabó y Termes cubre asimismo el comportamiento de los nuevos gobernantes africanos que imitarán y a veces superarán los desmanes de los europeos. ${ }^{8}$ De allí que Marvin Lewis sitúe a la novela de José Siale junto a Los poderes de la tempestad (1997) de Donato Ndongo Bidyogo y Huellas bajo la tierra (1998) de Joaquín Mbomio Bacheng: "Their collective message is that since its independence [...] Guinea has been subjected to a legacy of violence and brutality by its leaders, who act, ironically, in the name of nation-building. Each novel posed the question, How long will this nightmare last?" (179).

De todas formas, los pasajes de autocrítica y autorreflexión, acompasados con un dejo de estridencia sentimentalista en Cenizas de Kalabó y Termes no actúan como meros

8 La novela toca directa o indirectamente algunos temas de la sociedad en general: la violencia doméstica, la homosexualidad, el aborto; y de la sociedad africana en particular: poligamia y promiscuidad, la paupérrima consideración de la mujer, las actitudes dictatoriales y los abusos militares, la brujería y la superstición, los juicios sin garantías con ejecución injusta y la exculpación de chivos expiatorios una vez que la violación de derechos humanos salta a la prensa internacional (Nistal Rosique 124).

Revista Iberoamericana, Vol. LXXX, Núms. 248-249, Julio-Diciembre 2014, 967-985 
motivos de denuncia y ataque, sino como instrumentos para recobrar lo más profundo de una experiencia personal y para crear, a partir de ella, personajes y situaciones de total persuasión. En vez de hablar de alienación, de dominación y de los sistemas coloniales e imperiales de cultura, el autor narra desde ellos, convirtiéndolos en una visión artística cuya sordidez pintarrajeada inspira al lector más piedad que risa, más comprensión que condena. El objetivo de José Siale no es moralizar, sino más bien identificar al lector con lo que le produce rechazo, y explotar esa conmoción. Es en este punto donde la novela muestra su semblante más novedoso: apreciamos la actitud punzante del retrato pero nos olvidamos de que es nuestra caricatura. En la sociedad burguesa el emisor del mito se diluye, se identifica con el hombre universal que es el fundamento mismo de la sociedad moderna: quien habla no es un grupo o una clase, sino más bien una voz anónima y contestataria de la razón, y el contenido del mito se da como ley de orden natural, ocultándose así el proceso y la motivación de su emergencia.

En cuanto a aspectos estilísticos y formales, hay que señalar el tono de parodia, el circunloquio retórico y la refinada ironía que impregna toda la obra de Siale, a veces presentando anécdotas jocosas y otras veces suavizando temas de fondo brutal:

A Rosendo le sometieron al interrogatorio español [...] la paliza francesa, luego le ataron las muñecas al estilo Marruecos, enredándole a lo etíope para pasarle luego a la horca palestina donde le propinaron un puño americano [...] y le dieron la estocada africana $[\ldots]$ fue como la vuelta al mundo en ochenta palizas. (198)

Como ya ha ocurrido en otras partes del continente africano, a una primera reacción "antimetrópoli" (léase, los Ben Okri, Nuruddin Farah), las referencias al pasado se construyen a través de mecanismos comunes para interpretar tanto el pasado inmediato con el presente caótico. Como enlace entre la estrategia narrativa de revisión crítica del pasado, pero que también cuestiona hasta qué nivel el antiguo orden colonial ha realmente concluido o sobrevive bajo prácticas y símbolos posindependentistas autóctonos, se encuentra la novela corta Nambula de Maximiliano Nkogo Esono. ${ }^{9}$ Maximiliano Nkogo vuelve con esta novela a su característico estilo cargado de sarcasmo que utilizará para describir lo más negativo de la realidad. De cualquier manera, no hay que olvidar que en este libro se encuentra también un elemento esencial, constructivo, consistente en las propuestas para la mejora de un país emergente: "Nambula, un pueblo decidido a emerger [...] renovado" (110). Sin embargo, las primeras palabras de la novela son,

9 Nambula es un país inventado por la autora Helen Fielding en la novela Cause Celeb. En esta última, la protagonista, cansada de su vida burguesa en Europa, decide viajar al "Tercer Mundo" y organizar un concurso para ricos y famosos, cuyos beneficios pecuniarios se destinarán recolectar dinero para adquirir alimentos.

Revista Iberoamericana, Vol. LXXX, Núms. 248-249, Julio-Diciembre 2014, 967-985 
El vendaval de la democracia y su irresistible corriente multipartidista procedente del Norte levanta auténticos torbellinos de ambiciones fraticidas y sacude con portentosa fuerza los sagrados pilares sobre lo que hasta hoy se había asentado cómodamente el tradicional modo de ser del Sur. (5)

En este sentido, la novela se convierte en una crítica corrosiva a muchas sociedades del África subsahariana: "Nambula es un pequeño país del África negra, una ex colonia de varias potencias europeas" (5). Nambula es una descripción brutal, disfrazada de relato desenfadado e inocente, de la corrupción salvaje que azota a muchas ex colonias africanas y que afecta a todos los ámbitos de la sociedad. El argumento es sencillo: narra la fulgurante ascensión, con rito de iniciación incluido, y la posterior caída, de un sobrino de Jim Jimbo, segunda máxima autoridad de Nambula. El sobrino será nombrado Supervisor General encargado de recados y liberado de todas las acusaciones "de delitos de tráfico de estupefacientes, tenencia ilícita de armas e indocumentación que pesaban sobre él" (13). El sobrino, como es llamado continuamente en el libro, se encargará de ejercer a gran escala el oficio que practicaran con humildad Adjá-Adjá y su compañero en el cuento homónimo que Nkogo publica por primera vez en 1994, y de beneficiar a los allegados haciendo gala de la "solidaridad familiar africana". ${ }^{10}$

De forma inflexible y extorsiva el sobrino extraerá todo lo que pueda de empresas y ciudadanos, llegando hasta sus últimas consecuencias si es necesario. Habrá torturas, palizas y muertes, principalmente propinadas a los que se oponen al gobierno. Debido a sus excesos, el sobrino será llamado "de arriba" y deberá sufrir la humillación de ser reconvenido por el máximo Jefe del país, que es uno de los escasos personajes de la novela que es presentado de manera irónicamente positiva, como un gobernante cabal y responsable: "Estamos en proceso de materializar nuestro programa de democratización como paso previo [...] por eso voy a acabar con este estado de cosas que habéis creado y que no favorece ni a vosotros mismos" (99). ${ }^{11}$ El Jefe Supremo "[c]onoce muy bien a sus compatriotas" y sabe que "la mayoría de ellos miente, traiciona" (99), pero lo único que les pide en un arrebato de "fiebre democrática" es que "desechen las viejas prácticas y trabajen de verdad para que se produzca un profundo cambio de mentalidad" (99). De cualquier manera, el travestismo social que hace del dictador un hombre

${ }^{10}$ Nistal Rosique hace una muy buena sinopsis del texto: Adjá-Adjá, "migaja-migaja” en castellano, es el apodo de un policía de tráfico y de orden público que patrulla, junto con su compañero, las calles de Malabo. Al no recibir una paga digna, se ven obligados a hacer pequeñas extorsiones a los ciudadanos para salir adelante. Los cuentos son una representación paradigmática de la picaresca de las clases trabajadoras del país en su lucha para buscarse la vida a base de pequeños sobornos (adjá) y corruptelas. Una gran dosis de ironía teje todas las narraciones costumbristas que describen un Malabo de pillos de frescura sin igual (118).

${ }^{11}$ Como bien observa Marvin Lewis: "The State implores citizens to aid in nation-building, even though it is the State that has taken away the will, as well as the means, to carry out this enterprise" (176).

Revista Iberoamericana, Vol. LXXX, Núms. 248-249, Julio-Diciembre 2014, 967-985 
benévolo y justo puede tener por lo menos dos miradas: la que implica el esfuerzo de las autoridades guineanas contemporáneas para mejorar la situación del país gracias, entre otras cosas, al acicate producido por la explotación del petróleo antes referida; y otra, de raigambre meramente paródica, que hace convertir aquello que da miedo en la vida cotidiana en objeto de burla, rito que lo anula. Pero cuidado, ya que como advierte Linda Hutcheon: 'Ironic versions of 'transcontextualization' and inversion are its [de la parodia] major formal operatives, and the range of pragmatic ethos is from scornful ridicule to reverential homage" (36).

En lugar de esa graduación del "ethos" que va desde la burla al homenaje, el discurso paródico de Nkogo sostiene en cambio la coincidencia de ambos (burla y homenaje/ sumisión al mismo tiempo). El discurso paródico de Nkogo (bívoco y ambivalente) representa un bombardeo soslayado a la inhabilidad de los dogmas de un sistema ideológico y cultural machista y autoritario, base de la sociedad patriarcal y católica impuesta (por el europeo) y/o consensuada en Guinea. La crítica a este sistema ideológico y sociocultural no la realiza Nkogo mediante una sátira demoledora (del Jefe Supremo), ni mediante una ridiculización burlesca in extremis del mismo, sino a través de un dispuso bívoco, ambivalente, analítico que desfamiliariza al presentarnos lo familiar dentro de la imitación que desmitifica al mitificar. La parodia del dictador sirve para realizar un análisis crítico de los aspectos ideológicos y culturales sobre los que reposa la sociedad guineana y, por extensión, otras muchas sociedades (incluida la española, obviamente) basadas en los mismos principios de autoridad patriarcal y machismo dentro de una era capitalista maestra en el diseño y control del consciente e inconsciente colectivo (recordar cómo el Jefe Supremo "conoce muy bien a sus conciudadanos") por mediación de la propaganda de la "Santa Alianza Liberadora Occidental", como le denominaría el eximio escritor hispanomarroquí Ahmed Ararou, en el afán liberador de pueblos "menesterosos de protección” y “democracia" (“AMÉ...RICK” 62).

Como consecuencia del ejercicio de poder autocrático y tirano, el sobrino será cesado de su cargo. Después de su hundimiento moral y de su desesperación, el desenlace será inmediato. Será la picadura de una avispa, seguramente provocada por un acto de brujería, por el amuleto que debió ocultar, según la indicación del Consejo de ancianos, la que le provoque su precipitada muerte. Cabe decir también que la novela de Nkogo sirve fundamentalmente para introducir diversos temas de carácter social como la violencia de género, la emancipación de la mujer, el acceso igual a la educación o la lucha contra la ablación del clítoris, el maltrato a los detenidos, los juicios amañados, la libertad de expresión y la democracia, la mala situación de la sanidad pública y la escasa inversión pública en ella, y el tráfico internacional de alimentos infectados o caducados. Sin embargo, las voces de los personajes "secundarios" en esta novela no llegan a transgredir la autoridad del sobrino, se someten a ella, no llegan a expresar sino lo convencional a través de lenguajes fijos que vehiculan ciertos contenidos ideológicos

Revista Iberoamericana, Vol. LXXX, Núms. 248-249, Julio-Diciembre 2014, 967-985 
y mitologías, e imponen su propia realidad material a los personajes que los hablan y escriben. Ya dudaba Baudrillard sobre la capacidad del intelectual de proyectar la voz de los subalternos (48-49). Si bien las masas son el leitmotiv y obsesión de los discursos sociales que intentan hacer que los oprimidos hablen, dichos proyectos, continúa Baudrillard, acaban desintegrándose, "for the masses cannot be represented" (49). Un poco más optimista, pienso en términos gramscianos sobre "el pesimismo del intelecto y el optimismo de la voluntad", y observo que intelectuales como Nkogo combinan el escepticismo filosófico sobre el intento de recuperación de agente subalterno con el compromiso político de hacer visible la posición/voz de los marginalizados.

Ahora bien, consecuentemente, con la "muerte de perro" que padece el sobrino al final de la novela, nos damos cuenta que las transgresiones que ha cometido en su corta carrera de Supervisor General dura mientras dura el circo mediático, su manejo de influencias y sus atropellos hacia la sociedad civil, aunque indefectiblemente estando siempre bajo el panóptico del "de arriba", que regula la "transgresión autorizada". Al final, el orden es restaurado plenamente: el paria que había sido en Europa vuelve a ser el paria que muere solo e ignoto entre los vómitos y las sábanas sucias de un hospital que no posee siquiera un médico de guardia. En cambio, el Jefe Supremo seguirá siendo el Jefe Supremo y el orden social no habrá sufrido cambio alguno. Este procedimiento foucaultiano es concluyente ya que situar al subalterno (sin dudas, el sobrino es otro subalterno que "no se sabe vigilado") dentro de una multiplicidad de jerarquías no es suficiente; debemos pensar también en las relaciones cruciales interjerárquicas que determinan las diferentes fuerzas dentro de la estructura vertical de poder y su respectivos discursos ("las coacciones del poder", según Foucault 206). Volvemos, de esta manera, a la ambivalencia de la imitación (Bhabha, "Of Mimicry" 266-271), en tanto y en cuanto mientras la estratagema del sobrino es calculable a los usos de la disciplina hacia sus “temporales súbditos", lajustificación de sus acciones, la superstición, su espuria autoridad y la repetición del sentimiento de culpa (al final de la novela) pueden ser vistas como un desesperado esfuerzo por normalizar formalmente el desajuste de un discurso que viola la "racionalidad" del poder absoluto del Jefe. La ambivalencia del discurso neocolonial pasa de la mera imitación del superior (por parte del sobrino) al sentimiento de amenaza por parte de la autoridad jerárquica que, sin llegar a la preocupación paranoica que acabe en un posible golpe de estado, actúa lo suficientemente pronto como para sesgar la conducta "errática y excéntrica" del transitorio Supervisor.

Elisa Rizo ha analizado la narrativa de Juan Tomás Ávila Laurel de manera vehemente y exhaustiva. La crítica acierta al desmenuzar el aparato discursivo de refutación y negociación de la memoria guineoecuatoriana hecha por el escritor annabonés para concertar una retórica independiente del discurso historiográfico eurocentrista (197). En el afán de deconstruir el mencionado discurso historiográfico "moderno"(Rizo 198), Ávila Laurel se vale del marco novelístico confesional (se narra en primera persona y se hace

Revista Iberoamericana, Vol. LXXX, Núms. 248-249, Julio-Diciembre 2014, 967-985 
continua referencia al lector), propio de la picaresca, para desarrollar su última novela, Avión de ricos, ladrón de cerdos. La novela, en la que resaltan sucesos aparentemente aislados y anacrónicos, parte de un episodio irrisorio en el que dos muchachos, primos, se aventuran a la caza de dos cerdos que se escapan de un avión que está a punto de transportarlos de Bata a Malabo. Tras los cerdos corren también los esbirros de "El Jefe", un acaudalado miembro de la plutocracia guineana con conexiones en el gobierno, que no sólo recupera a los porcinos sino que toma como rehenes a los dos jóvenes para ser transportados a Malabo. Nos enteramos más adelante en la novela que ambos jóvenes iban ser sacrificados en un rito de brujería que daría comienzo al establecimiento de un hotel de lujo en el interior de Malabo. Los jóvenes salvarán su pellejo debido a la mención de los contactos/miembros de su familia, todos ellos variopintos personajes que a su vez conforman el corpus narrativo de la novela.

El que narra la historia es uno de los primos. Entre las infinitas historias contadas en la novela es menester resaltar -aparte de los ya observados contrastes entre la transición de la colonia, el régimen de Macías, la sempiterna corrupción, el clientelismo político actual, los discursos contrastivos entre modernidad y la tradición, y las dicotómicas dinámicas de género sexual-, los conflictos interétnicos que existen en Guinea, la relación neocolonialista entre ciudadanos españoles que realizan turbias labores comunitarias en el país centroafricano y el surgimiento de una pseudoaristocracia guineana cuya representación en la narrativa de Ávila Laurel no hace más que emplear una burlesca sátira con aroma africano de una realidad al mejor estilo Berlusconi y su "Villa Certosa" o, más acorde al panorama "tercermundista", Carlos Menem y su "Rosadita". Muchas veces la crítica hacia las mujeres que explotan su cuerpo para conseguir escalar en el ámbito de la mencionada aristocracia es despiadada y presenta ciertos matices misóginos, particularmente cuando se hace mención a las mulatas corisqueñas que buscan aparearse con peces gordos adscritos al poder de turno, o de las muchachas ndowé que "se lían" siempre con blancos (123). No tiene desperdicio la narración del médico español y pedófilo Edú, al que pone en descubierto el narrador de la novela, delación que produce la expatriación del europeo y la denuncia de los compatriotas del narrador/personaje que soportan las vejaciones del galeno con tal de obtener alimento, refugio y contención: " $[\mathrm{N}]$ osotros no disfrutábamos de todas aquellas cosas porque aquello doctor fuera nuestro padre [...], sino que todo en esta vida tiene un precio [...]., quien pone comida, bebida, casa y protección es porque quiere algo a cambio" (88). Hábilmente, el narrador liga la historia de sometimiento de los "protegidos" por el médico español con la de los torturados por el nuevo régimen ya que ambos casos "los ultrajados" callan sus historias por vergüenza y para que "los husmeadores extranjeros" emitan juicios de valor hacia los africanos (168).

Como contraparte del médico español, aunque no menos paternalistay definitivamente ligada a la estructura patriarcal-que incluye mecanismos de coerción física y psicológica-,

Revista Iberoamericana, Vol. LXXX, Núms. 248-249, Julio-Diciembre 2014, 967-985 
emerge la figura de Yamambé Yamambó, abuelo del narrador y becario del gobierno cubano para realizar estudios de medicina, que al final deserta para dedicarse al estudio de un poeta negro que marcaría su existencia y su vocación de cuentacuentos oficial de Bata, luchador por la independencia del país, forjador del nuevo régimen nacional (del que nunca recibió compensación alguna), obstetra circunstancial (comprendiendo el tratamiento de los aspectos psicológicos y sociales de las parturientas que se le asignan al "profesional") y padre putativo y/o real de centenares de niños: Yamambé fue el que "más hijos trajo al mundo, ya fuera por su profesión o por su erección" (202). La referencia a que el narrador posee las mismas "cualidades" que su abuelo prefiguran un futuro no muy promisorio de la nación. Tal es así que la novela termina narrando cómo el personaje principal se convierte en una suerte de banquero del mismo hombre que lo secuestró, sisando parte de la fortuna de este último para ir forjando poco a poco su propio imperio.

Y de allí, casi al final de la novela, leemos que el propio narrador/personaje cuenta su historia (se convierte también en autor) "a sabiendas de que a alguno le disgustará", pero que de cualquier manera es su intención "que sepan [los lectores] que cuent[a] desde la sinceridad, sin omitir nada, por más censurable que parezca [su confesión], al menos a ojos de los blancos, para no decir extraños" (239). La apelación al recurso metatextual insinúa que la "anatomía del poder" (Foucault 218), lejos de desaparecer, crea, otra vez, una irónica ambivalencia: el narrador es víctima y modelo de lo censurable (corrupción, tribalismo, nepotismo), factores que implican, por un lado, transmitirle al lector propósitos que le son hostiles en una suerte de unamuniano "dejar turulato al hortera" (¿europeo?), pero por otro lado, la enunciación del narrador-personaje-autor converge con la enunciación previa que le sirve de intertextualidad (las historias del médico pedófilo español y de Yamambé) y que culmina en la "estilización" (Todorov 70), modelo híbrido de escritura contestataria que parece seguir gran parte de los "novocostumbristas" guineoecuatorianos y que César Mba, como veremos más adelante, acabará por consagrar. ${ }^{12}$

12 En consonancia con lo dicho, poco antes de su muerte, el escritor afrohispano Blas Jiménez abogaba por apartarse del "europeo-centrismo que apesta a muerte" y apuesta a abrir las brechas "de la conciencia extraeuropea". De esa manera, el escritor afrohispano va haciendo las reglas con sus propias reacciones personales, dentro del universo comunal africano: "Vamos creando nuestros sonidos, defendiendo nuestras fronteras, dándonos libertad... Viviendo nuestra estética" (bastardillas mías, 3, 5). Por su parte, en una nota aparecida tres años antes de la publicación de Avión de ricos, Ávila Laurel menciona el alto índice de analfabetismo en Guinea y se opone tanto al auge de las corrientes "globalizadoras y desvalorizadoras" de lo nacional y al monopolio de las multinacionales de la edición. Urge a los escritores guineoecuatorianos a "dar un golpe" y ofrecer a la "sociedad internacional" un producto que "suscite la suficiente atención para ser tenida en cuenta, como ya ocurrió con el llamado boom latinoamericano, salvando, claro está, diferencias, distancias, circunstancias y dimensiones" ("Notas"172).

Revista Iberoamericana, Vol. LXXX, Núms. 248-249, Julio-Diciembre 2014, 967-985 
Lo anterior me lleva a la conclusión de que en las novelas de Siale, Nkogo y Ávila Laurel que he analizado, algunos personajes se convierten en protagonistas involuntarios de una situación que en muchos casos desaprueban y que critican a través de representaciones exageradas y grotescas de demostraciones de poder carismático y humorísticas malinterpretaciones de rudimentos políticos occidentales. Existe, de esta forma, una representación de elementos tradicionales africanos que se circunscriben de manera antinatural en un proceso de fosilización que choca de manera contundente con lo que parece ser una reproducción dislocada o fuera de contexto de modelos sociopolíticos occidentales. Entre los elementos comunes que encontramos en esta "Nueva narrativa nacional" se observa la coexistencia de motivos tradicionales (amuletos, fetiches, brujería, ritos de iniciación, griots), copias de forma de vida occidentales y actuaciones diplomáticas esperpénticas narradas de manera histriónica e injertadas en una sociedad africana en las que no cuajan: comidas autóctonas con botellas de CocaCola, desenvueltas ropas informales con formalísimos y constrictivos complejos de la afectividad e iracundos mensajes antiimperialistas con deslumbrada aceptación de la mass culture. Los distintos pasajes hipercríticos y tragicómicos son incorporados en los textos satíricamente, ridiculizando no sólo las prácticas políticas africanas, sino también sus modelos originales occidentales, expresando, por consiguiente, la desilusión del periodo poscolonial y sobrepasando, simultáneamente, la "retórica de denuncia" (Said 19) contra Occidente. Este proceso de transculturación sufrido por la "Guinea moderna" y las contradicciones que en él subyacen, adquiere unas características muy particulares al tender más hacia la emulación que hacia la configuración de esa especie de monstruo bicéfalo, resultante en la mayor parte de la inevitable confluencia entre lo autóctono y lo extranjero. En síntesis, los escritores de la "Nueva narrativa nacional" comparten con otras literaturas africanas dos temas fundamentales: la colisión entre las formas modernas de vida y la tradición, y la necesidad de reconciliar el pasado y el presente. Por ende, utilizan la literatura como agente de transformación social y consideran que, si bien es cierto que las ideas de modernidad europea no pueden ser validadas, tampoco lo consigue la noción de "nueva república africana", tan falaz y decepcionante como la anterior.

El siglo XXI marca un periodo de dinámica coexistencia entre los productores culturales guineanos de las dos últimas décadas con el que considero el trabajo literario parte aguas de César Mba Abogo, quien en 2007 con El porteador de Marlow. Canción negra sin color combina cuentos, prosa poética y poesía en un decálogo descriptivo, desgarrado y profundo de un África desarraigada y de una Europa despiadada, cuyo nexo, espectador y habitante, es el propio autor. ${ }^{13}$ El libro toca temas de completa actualidad

13 Como observa Nistal Rosique (217), la violencia aparece reflejada con varias caras; la violencia de género ("Hijo de mujer"), ("Historia privada de un superviviente") y la violencia de los uniformes, la

Revista Iberoamericana, Vol. LXXX, Núms. 248-249, Julio-Diciembre 2014, 967-985 
en el África poscolonial: corrupción, atraso, falta de recursos básicos como el agua y la luz, emigración; y en la Europa del siglo xxi: pobreza, violencia, racismo, xenofobia, inmigración e incomprensión, matizados con una sutil ironía y un sentido del humor que lo equiparan con los mejores escritores africanos en lengua castellana. ${ }^{14}$ Aunque las narraciones son independientes, es la historia de un viaje de ida y vuelta, desde Puerto Fraga (Malabo), situada en Franquicia (Guinea Ecuatorial) hasta Soladia (España), cuya capital es Amilcarna (Madrid), y la vuelta de Soladia a Franquicia. Definitivamente se trata de una literatura citadina, por lo que no es curiosa la intertextualidad explícita con Le città invisibili de Italo Calvino, un juego literario al fin también interconectado con los viajes y aventuras del Occidente de Marco Polo y el Lejano Oriente de Gengis Khan.

Al mismo tiempo, el libro de César Mba introduce un nuevo objeto literario de difícil clasificación, en tanto y en cuanto posee su propio código descifratorio. La configuración del libro es poliédrica, subvirtiendo los muchas veces rígidos procedimientos narrativos europeos acordes al discurso realista burgués, monocorde, autoritario y monológico para, de esta forma, conseguir sublimar un sentido estético flexible y pragmático, un discurso dialógico, polifónico, ambivalente y subversivo, consecuente con las tradiciones orales africanas "trémula[s] y creativa[s]" (Glissant 41), pero lo suficiente consciente de no caer en la fragmentación posmodernista, desligada de cualquier preocupación social, teniendo como norte los defasajes que produce el capitalismo global. El concepto escriturario que propone Mba tiene un triple sentido: es histórico, es social y es estilístico. En este orden, también se deja ver en El porteador de Marlow la inscripción de la cultura popular y de masas de manera ambivalente, ya que por una parte revaloriza los géneros considerados "menores" (folletines, canciones, mundo televisivo), y por otra, se distancia de estos modelos, al inscribirse dentro de los márgenes de esa otra Literatura con mayúsculas, minoritaria y elitista (T. S Elliot, Richard Wright, Wole Soyinka, Pablo Neruda). A la misma vez, la literatura de Mba se aparta incluso de los modelos narrativos de sus contemporáneos guineanos, ostentando, en cambio, un espacio contingente intermedio que innova e interrumpe el discurso del pasado: "Estoy condenado a vivir en una frontera/En la desidia ambigua y en la tormenta del exilio" (100); un espacio liminal, en definitiva, situado entre un crisol de designaciones

de los militares ("El país en que los rayos de locura y muerte devoran el cielo"), ("Historia privada de un superviviente"). Por su parte, el tema de la emigración se trata en el libro profusamente, desde distintos puntos de vista, como viaje sin retorno ("En algún lugar bajo el Atlántico"), como el lugar de la incomprensión y la discriminación, con graves problemas por el color de la piel (Me han hecho la vida más cansada y pesada), ("El porteador de Marlow"), ("What a wonderful World"), ("Hora de partir") o ("Los hermanos de Senghor"), éste último tratado con una infrecuente ironía en el estilo del autor, de visión siempre dolorosa e intimista. Otro tema será la lamentable situación de pobreza y abandono de ciudades africanas como la irreal Karabumete, donde la basura se amontona, hay hambre y no hay agua corriente ("Historia privada de un superviviente").

14 Véase Ricci, "La literatura marroquí".

Revista Iberoamericana, Vol. LXXX, Núms. 248-249, Julio-Diciembre 2014, 967-985 
de identidad (Bhabha, Location of Culture 5, "la identidad como rizoma [...] de raíz múltiple", Glissant 25, 66, 132). Este locus intersticial, ceñido a monolíticas y opuestas identidades, ofrece una perspectiva hibridizante que no sólo negocia la diferencia sin la necesidad de la presencia de jerarquías identitarias, sino que también ensaya una nueva definición literaria que tiene como objetivo el nuevo posicionamiento del sujeto colonial con respecto a su relación con la antigua metrópolis colonial (condición sine qua non para Ngũgĩ wa Thiong'o 165 y Glissant 17). De allí que Europa (España) ya no es observada y representada como el ego simbólico absoluto que suscita el rechazo poscolonial o como la trampa ontológica para la expresión creativa del Otro; en cambio es representada como el escenario ambivalente de la novedad:

$[\mathrm{N}]$ o paro de avergonzarme de mi cotidianeidad en esa Europa en la que soy a la vez hijo y forastero [...]. Pero, por mi parte, cuanto más intento vaciarme de las nomenclaturas de la historia para ser transparente como la conjunción de varios neo-mundos que forman un todo-mundo inédito que ignora las nociones de centro y periferia y del que ninguna sociedad es metrópolis de otra, el lamento de Walcott en su A Far Cry From Africa, ya sea en forma de mosquitos o libélulas, siempre acaba llegando hasta mí y aplastándome bajo su peso. (123)

El dialogismo subversivo que intenta "nivelar" (Glissant 19) el discurso Norte-Sur a través de la literatura debe lidiar simultáneamente una fragmentación social e ideológica embebida en un lenguaje singular que evoca a la Europa-propia y a la Europa-Otra: "He vivido en Europa/ He vivido en el paraíso/ He vivido en el infierno/ Cuando me reúna con mi gente/ Hablaré de los hombres y las mujeres de Europa/ Hombres y mujeres como nosotros" (98). La desafiante y a la vez estimulante división producida en el locus de enunciación está perfectamente definida en un episodio onírico de uno de los personajes: "Mantuvo una conversación indescifrable con un hombre muy extraño. Tenía dos bocas, una estaba donde están las bocas habitualmente y la otra estaba en la nuca [...] Hablaron como si fueran miembros de una familia desunida y extensa" (51). En consecuencia, los entrecruzamientos fronterizos de las diferencias culturales pueden ser tanto consentidos como conflictivos y, por cierto, como se puede precisar en los textos de Mba, el sujeto poscolonial tiene ahora dos bocas/dos lenguas con las que puede hablar, una "donde debe estar" y la otra escondida, aunque no silenciada.

Para finalizar el análisis sobre El porteador de Marlow creo conveniente no soslayar las referencias a las ciudades del Norte y del Sur, en tanto y en cuanto el espacio urbano ofrece la necesidad de abordar el fenómeno emergente de las "ciudades-frontera literarias" (García Canclini 298), que necesariamente necesitan ser renombradas (de allí Amilcarna y Puerto Fraga, como en Autorretrato con un infiel Poór Donanfer, Isco de Corr y otras) para poder designar la contemporánea realidad de la transculturación en un proceso de amplificación de la diversidad discursiva y cultural. Mba explora

Revista Iberoamericana, Vol. LXXX, Núms. 248-249, Julio-Diciembre 2014, 967-985 
las estructuras lingüísticas que determinan el vaciamiento y la petrificación del lugar común, la ausencia de valores que crea la necesidad de imponer un espacio de valores apócrifos. Dentro de este ambiente contrapuntístico, tanto la realidad del lugar de origen como las ciudades de acogida son evaluadas en una posición incómoda-inestable ("unhomely" diría Bhabha) a través de una percepción liminal específica: "Puedo vivir sin las columnas los templos o los palacios de Europa/Puedo vivir sin Florencia, son los Beatles, sin Calvino.../Pero cada vez que tengo listas las maletas/La sombra del miedo se abalanza sobre mí" (131). Por lo tanto, el escritor-personaje-voz poética no es completamente africano, aunque tampoco europeo, sino más bien es transformado en una significativa construcción de una identidad liminal en un periodo neo-identitario, posexistencialista ("identidad trascendida", diría Glissant 98).

Concluyo este artículo con algunas ideas de Frantz Fanon, Aimé Césaire, Édouard Glissant, Mohamed Abd Al-Jabri y Néstor García Canclini respecto al tándem creación literaria-"cultura nacional" (198-219), que se ajustan, si bien con ciertos matices, a todos los textos analizados en este artículo. Por un lado, es necesario que el escritor guineano articule en sus textos cómo el colonialismo trata de aniquilar las representaciones socio-culturales de los colonizados priorizando la ayuda económica para solventar los problemas producidos por el "subdesarrollo", el "paganismo", las "supersticiones", los "fanatismos" y el "barbarismo". El colonizador no se satisface meramente anulando cualquier posibilidad de pensamiento crítico del colonizado; debido a su lógica pervertida, el colonizador hurga en el pasado de los oprimidos para manipularlo, desfigurarlo y destruirlo. Por ende, es la responsabilidad del intelectual guineano defender la legitimidad de su nación (y, por extensión, la de toda África negra) y, del mismo modo, ser capaz de "desnudarse" ("to strip himself naked", Fanon 201) para estudiar la historia de su cuerpo, de su identidad y obligado a "diseccionar el corazón de su gente" (201). En el afán de ser uno mismo sin cerrarse al otro y aprender cómo tolerar al otro sin renunciar a sí mismo (Glissant 39), el intelectual crítico moderno es el que controla, maneja la elección de instrumentos modernos hegemónicos (europeos) y tradicionales que le serán útiles tanto para la reconstrucción crítica de su propia tradición como para la evaluación de las culturas neocolonizantes (Al-Jabri 226). Porúltimo, la novísima narrativa guineana parece estar dispuesta a encarar el fenómeno de hibridación cultural en respuesta y apoyo a la modernidad polisémica poscolonialista y asumir el reto de la mundialización desde su posición periférica, para afirmar que el valor de una cultura depende del grado de "ósmosis", de "interacción" y de "diálogo que entabla con otras culturas" (Césaire 11, Glissant 26). En resumen, a lo que apuntan los autores seleccionados en este trabajo, pero especialmente César Mba, no es sólo a la resignificación y refuncionalización de lo tradicional desde lo moderno; sino también a la reubicación de las culturas antiguas en la compleja trama de la interculturalidad contemporánea (García Canclini 41).

Revista Iberoamericana, Vol. LXXX, Núms. 248-249, Julio-Diciembre 2014, 967-985 


\section{BIBLIOGRAFÍA}

Al-Jabri, Mohammed Abd. Crítica de la razón árabe. Barcelona: Icaria, 2001.

Ararou, Ahmed. "AMÉ...RICK". La puerta de los vientos. Narradores marroquíes contemporáneos. Barcelona: Destino, 2004. 58-64.

Ávila Laurel, Juan Tomás. Avión de ricos, ladrón de cerdos. Barcelona: El Cobre, 2008. "Notas sobre la Literatura de Guinea". Hispanic Research Journal 6/2 (2005): 171-173.

Baudrillard, Jean. In the Shadow of the Silent Majorities... or the End of the Social and Other Essays. Nueva York: Semiotext(e), 1983.

Bhabha, Homi K. The Location of Culture. Nueva York: Routledge, 1995. "OfMimicry and Man: TheAmbivalence of Colonial Discourse". Postcolonialisms. An Anthology of Cultural Theory and Criticism. Gaurav Desai y Supriya Nair, eds. Nueva Jersey: Rutgers UP, 2006. 265-273.

Césaire, Aimé. Discourse on Colonialism. 1955. Nueva York: Montly Review P, 1972. Fanon, Frantz. "On National Culture". Postcolonialisms. An Anthology of Cultural Theory and Criticism. Gaurav Desai y Supriya Nair, eds. Nueva Jersey: Rutgers UP, 2006. 198-219.

Foucault, Michel. “El panoptismo”. Vigilary castigar. México: SigloXXI, 1993. 199-230.

García Canclini, Néstor. Culturas híbridas: estrategias para entrar y salir de la modernidad. Buenos Aires: Paidós, 2001.

Glissant, Édouard. Introducción a una poética de lo diverso. 1996. Barcelona: Ediciones Del Bronce, 2002.

Gordimer, Nadine. The Black Interpreters: Notes on African Writing. Johannesburgo: Spro-Cas/Ravan, 1973.

Hutcheon, Linda. Theory of Parody: The Teachings of Twentieth-Century Art Forms. Nueva York: Methuen, 1985.

Jiménez, Blas. "El escritor afro-hispano y el proceso creativo". Afro-Hispanic Review 21/1-2 (2002): 3-8.

Lewis, Marvin A. An Introduction to the Literature of Equatorial Guinea. Columbia: U de Missouri, 2007.

Mba, César. El porteador de Marlow. Canción negra sin color. Madrid: Sial, 2007.

Ngara, Emmanuel. Stylistic Criticism and the African Novel: A Study of the Language, Art and Content of African Fiction. Londres: Heinemann, 1982.

N'Gom, Mbare. "Literatura africana de expresión española". Cuadernos Centro de Estudios Africanos 3 (2003): s/p

Nistal Rosique, Gloria. "Imagen de Guinea Ecuatorial en el siglo XXI a través de su literatura”. Oráfrica, revista de oralidad africana 4 (2008): 101-128.

Nkogo Esono, Maximiliano. Adjá-Adjá yotros relatos. Malabo: Centro Cultural Hispano Guineano, 1994.

Revista Iberoamericana, Vol. LXXX, Núms. 248-249, Julio-Diciembre 2014, 967-985 
Nambula. Malabo: Morandi, 2006.

Ngũgĩ wa Thiong'o. "The Language of African Literature". Postcolonialisms. An Anthology of Cultural Theory and Criticism. Gaurav Desai y Supriya Nair, eds. Nueva Jersey: Rutgers UP, 2005. 143-168.

Ricci, Cristián H. "African Voices in Contemporary Spain”. Hispanic Issues. En prensa. "La literatura marroquí de expresión castellana en el marco de la transmodernidad y la hibridación poscolonialista". Afro-Hispanic Review 25/2 (2006): 89-107.

Rizo, Elisa. "La carga de Juan Tomás Ávila Laurel: novela historiográfica poscolonial guineoecuatoriana”. Arizona Journal of Hispanic Cultural Studies 8(2004): 197-204.

Said, Edward. Orientalismo. 1978. Presentación de Juan Goytisolo. Barcelona: Debolsillo, 2003.

Senghor, Léopold Sédar. "Negritude: A Humanism of the Twentieth Century". Postcolonialisms. An Anthology of Cultural Theory and Criticism. Gaurav Desai y Supriya Nair, eds. Nueva Jersey: Rutgers UP, 2005. 183-190.

Siale Djangany, José. Autorretrato con un infiel. Barcelona: El Cobre, 2007. Cenizas de Kalabó y Termes. Ávila: Malamba, 2000.

Todorov, Tzvetan. "Intertextuality". Mikhail Bakhtin: The Dialogical Principle. Minneapolis: U de Minnesota, 1984. 323-334.

Walcott, Derek. “The Caribbean: Culture or Mimicry?". Postcolonialisms. An Anthology of Cultural Theory and Criticism. Gaurav Desai y Supriya Nair, eds. Nueva Jersey: Rutgers UP, 2006. 257-264. 
